\title{
Feasibility of the Simultaneous Determination of Polycyclic Aromatic Hydrocarbons by Near Infrared Spectroscopy
}

\author{
Sang Hak Lee, Jae Jak Nam, and Bum Mok Son \\ Department of Chemistr, Kumgpook National Cniversity, Daegu 702-701. Korea \\ ${ }^{\dagger}$ National Institute of Agricultural Science \& Technologi, Suwon 411-707, Korea \\ Recewed November 18, 2002
}

Key Words : Polỵç̣clic aromatic hỵdrocarbons. Partial least squares. Near infrared spectroscopy

Polycyclic aromatic hydrocarbons (PAHs) are widely distributed in the environment and are often implicated as potential carcinogens. Different methods such as liquid chromatography with spectrophotometric or spectrofluorimetric detection. capillary gas chromatography with mass spectrometric detection and supercritical fluid chromatography have been used to determine PAHs. ${ }^{1, \hat{2}}$ The chromatographic methods of quantitative determination of PAHs in environmental samples are costly time consuming. and unable to account for all kinds of PAHs. Recently the application of near infrared (NIR) spectroscopy to the deternination of environmental samples is growing fast since it is rapid and non-destructive with less sample preparation time. ${ }^{3}$

Multivariate tecluiques are particularly suited for the determination of mixture conposition from complex spectral data. One of the most popular multivariate techniques is the partial least squares regression (PLSR) that has been extensively described in chemonatrics literatures. ${ }^{4.7}$

The principle of PLSR is a modeling procedure that simultaneously estimates underlying principal component score metrics ( $\mathbf{T}$ and $\mathbf{U}$ ) and error metrics ( $\mathbf{E}_{\mathbf{X}}$ and $\mathbf{E}_{\mathbf{Y}}$ ) in both spectrometric data set $(\mathbf{X})$ and concentration data set (Y) ${ }^{8,9}$

$$
\begin{gathered}
\mathbf{X}=\mathbf{T P}+\mathbf{E}_{\mathbf{X}} \\
\mathbf{Y}=\mathbf{U}_{\mathbf{Q}}+\mathbf{E}_{\mathbf{Y}} \\
\mathbf{Y}=\mathbf{T B Q}+\mathbf{E}_{\mathbf{Y}} \\
\operatorname{RMSEP}=\sqrt{\frac{\sum\left(c_{a}-c_{p}\right)^{2}}{n}}
\end{gathered}
$$

The factors is calculated by using nonlinear iterative partial least squares (NIPALS) algorithm. ${ }^{1 j, 11}$ The PLS model is constructed by estinating inner relation (B) between the score for spectral data set $(\mathbf{T})$ and concentration data set (U) ${ }^{1 \dot{ }}$ The model validity can be evaluated by calculating root mean square errors of prediction using actual concentration $\left(c_{a}\right)$ and predicted concentrations $\left(c_{p}\right)$ of calibration data set which is consisted of $n$ numbers of sample. . $^{4.13}$

This work describes a quantitative spectroscopic method to analyze mixtures of eight PAHs using multivariate calibration models for Fourier transform near-infrared (FT-NIR)

\footnotetext{
To whom correspondence should be addressed. Phone: +82-53-
} 950-5338; Fax: +82-53-950-6330; e-mail: slleetalknuacks spectral data. The constructed model validity was evaluated by estimating RMSEP.

\section{Experimental Section}

Samples. The PAHs used in this study were antluacene, pyrene. benzo(a)anthracene. perylene. chrysene. benzo(a)pyrene. I-methylantluracene and benzo(ghi)perylene. The PAH mixture solutions were prepared by dissolving appropriate amount of each PAH standard in dichloromethane, and the numbers of standard solution were 100 for calibration and 40 for validation. The concentration range of each PAH was distributed from 0 to $260 \mathrm{mg} \mathrm{L}^{-1}$.

NIR spectra. NIR spectra of PAH solutions were recorded using a InfraProver II FTIR spectrometer (BRAN+LUEBBE. Germany). The spectra were measured in the region of $10000-4000 \mathrm{~cm}^{-1}(1000-2500 \mathrm{~mm})$ with interval of $12 \mathrm{~cm}^{-1}$ in transmittance mode using a quartz cuvette with $1 \mathrm{~cm}$ pathlength. The background was measured by using pure dichloromethane. The spectral data were processed using a partial least squares regression method.

Partial least squares regression. The PLSR method was used to make a model correlating $\mathbf{X}$ and $\mathbf{Y}$, where $\mathbf{X}$ contains the NIR spectra and $\mathbf{Y}$ is a metrics containing the properties of interest. The model performance was validated by means of the cross validation. ${ }^{4}$ Multivariate calibration models were

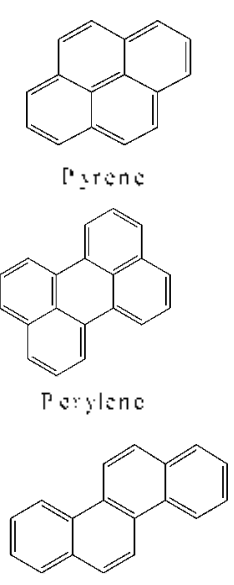

Chrssens

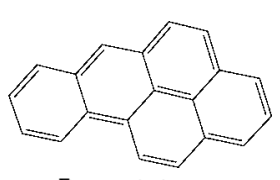

Bin<u(a)pyes:lc

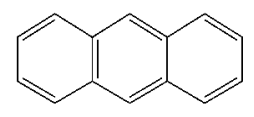

Anthraceste

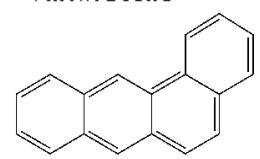

Bencosantaracis

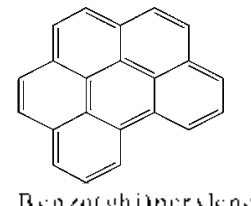

Rai)/o(ghimpers]cns

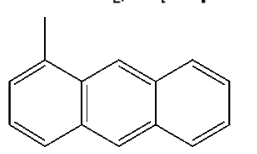

IAsthalatheracene
Figure 1. The structures of PAHs used in this study 
built to correlate the NIR spectra and the concentrations of PAHs. The PLSR method used in this study was performed by using the SESAME program (ver. 3.1. BRAN+LUEBBE. Germany). The predictive performances of the PLSR models were assessed by RMSEP(root mean squares error of prediction) criterion.

\section{Results and Discussion}

For the quantitation of PAHs the NIR specta of PAH mix- ture solutions which contain different amounts of pyrene, benzo(a)pyrene, benzo(ghi)perylene. perylene, antluracene, 1-methylantluracene, clurysene and benzo(a)anthracene were measured. The structures of PAHs used in this work are presented in Figure 1.

The second derivative was performed on raw NIR spectra using the whole wavelength range to correct for the baseline slifts and the handling scatter effects. Figure 2 shows the spectra of benzo(a)pyrene(BaP) in different concentrations. In Figure 2 the distinct spectral feature around $5280 \mathrm{~cm}^{-1}$ is

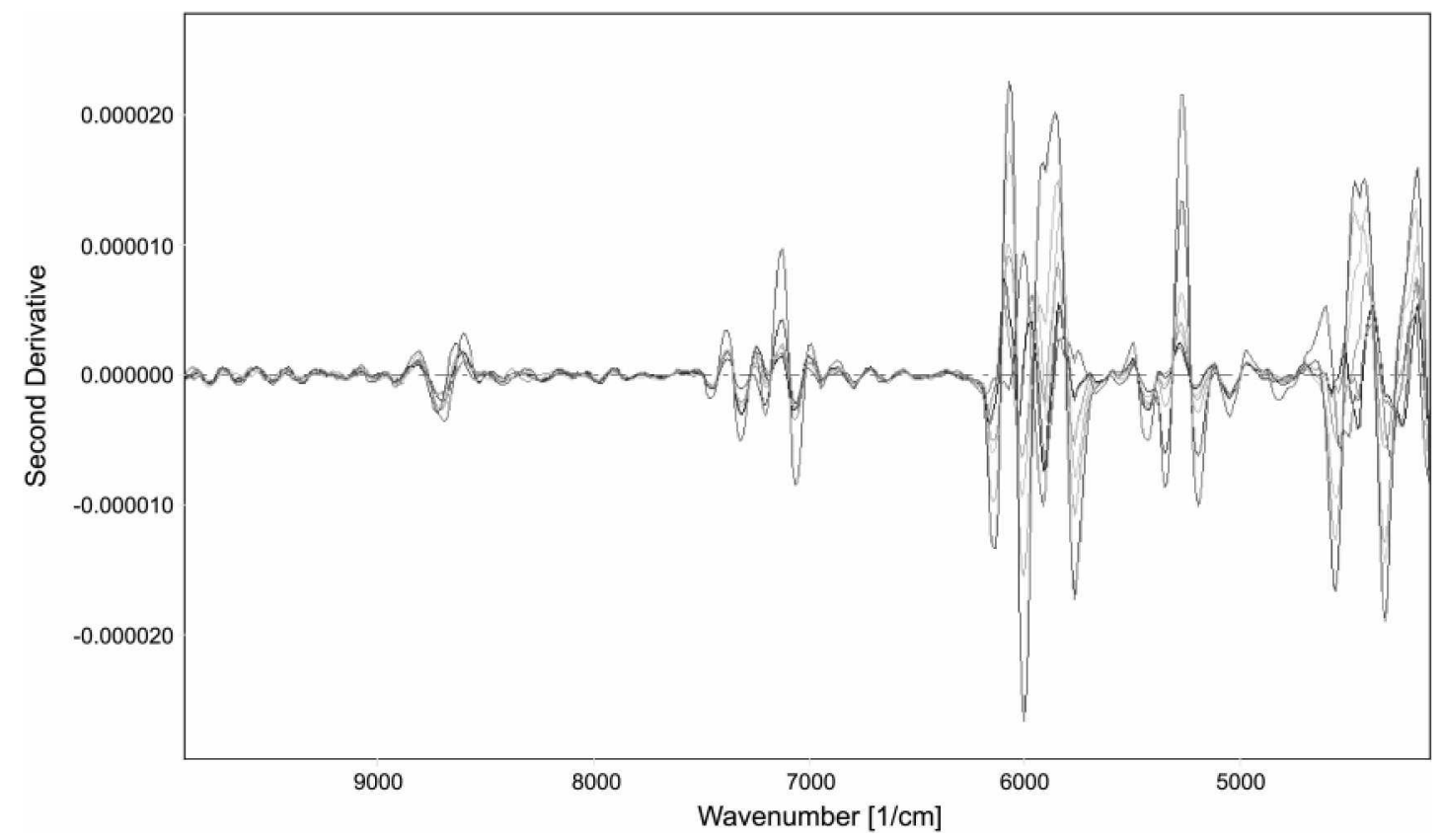

Figure 2. The second denvative near intrared spectra of benzo(a)pyrene m dichloromethane solutions: The concentration for each spectrum is $100,50,25,12.5,6.25,3.13$ and $1.56 \mathrm{mg} \mathrm{kg}^{-1}$, respectively.

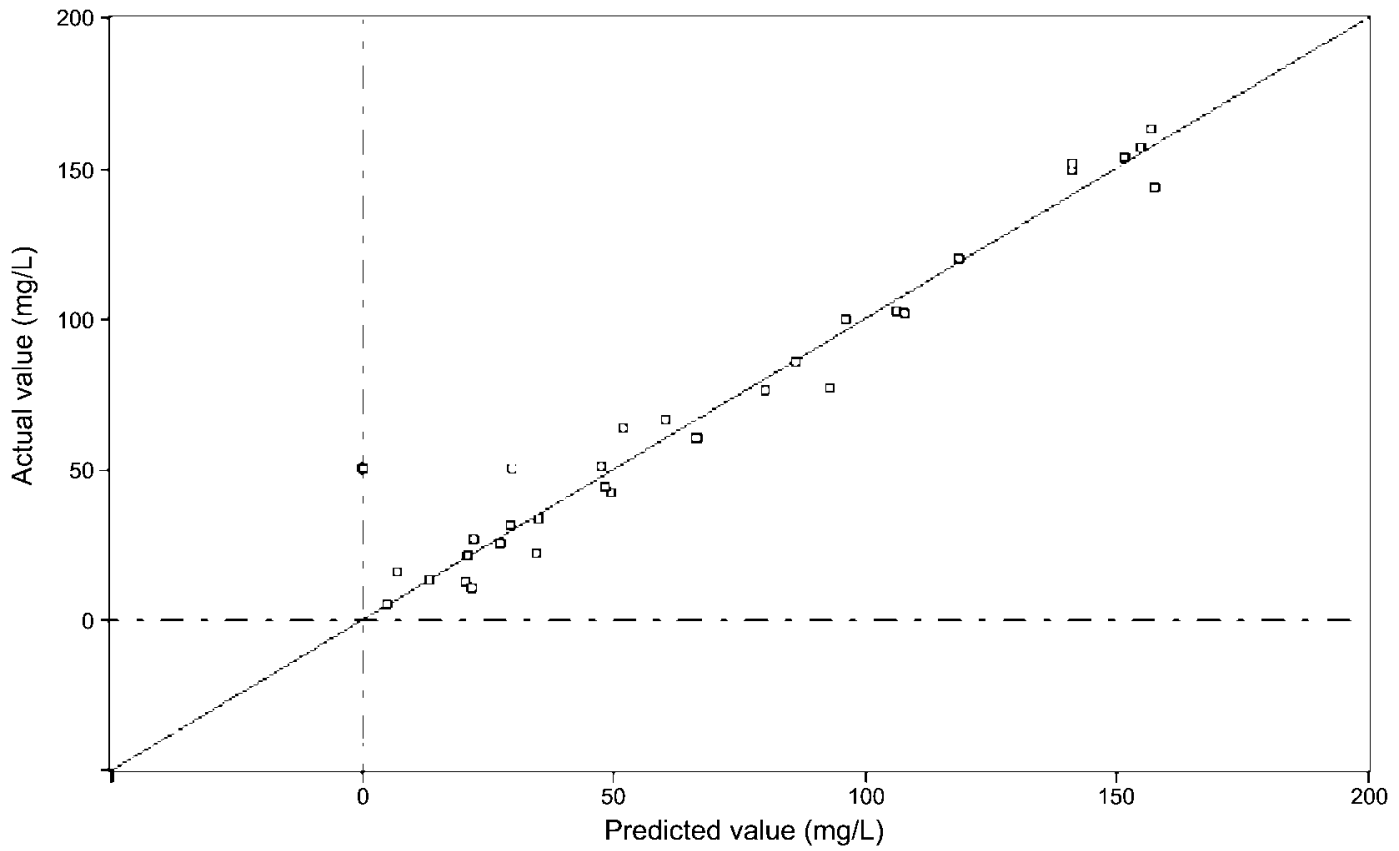

Figure 3. Relationship between the actual total PAHs contents and the NIR predicted values by PLSR. 


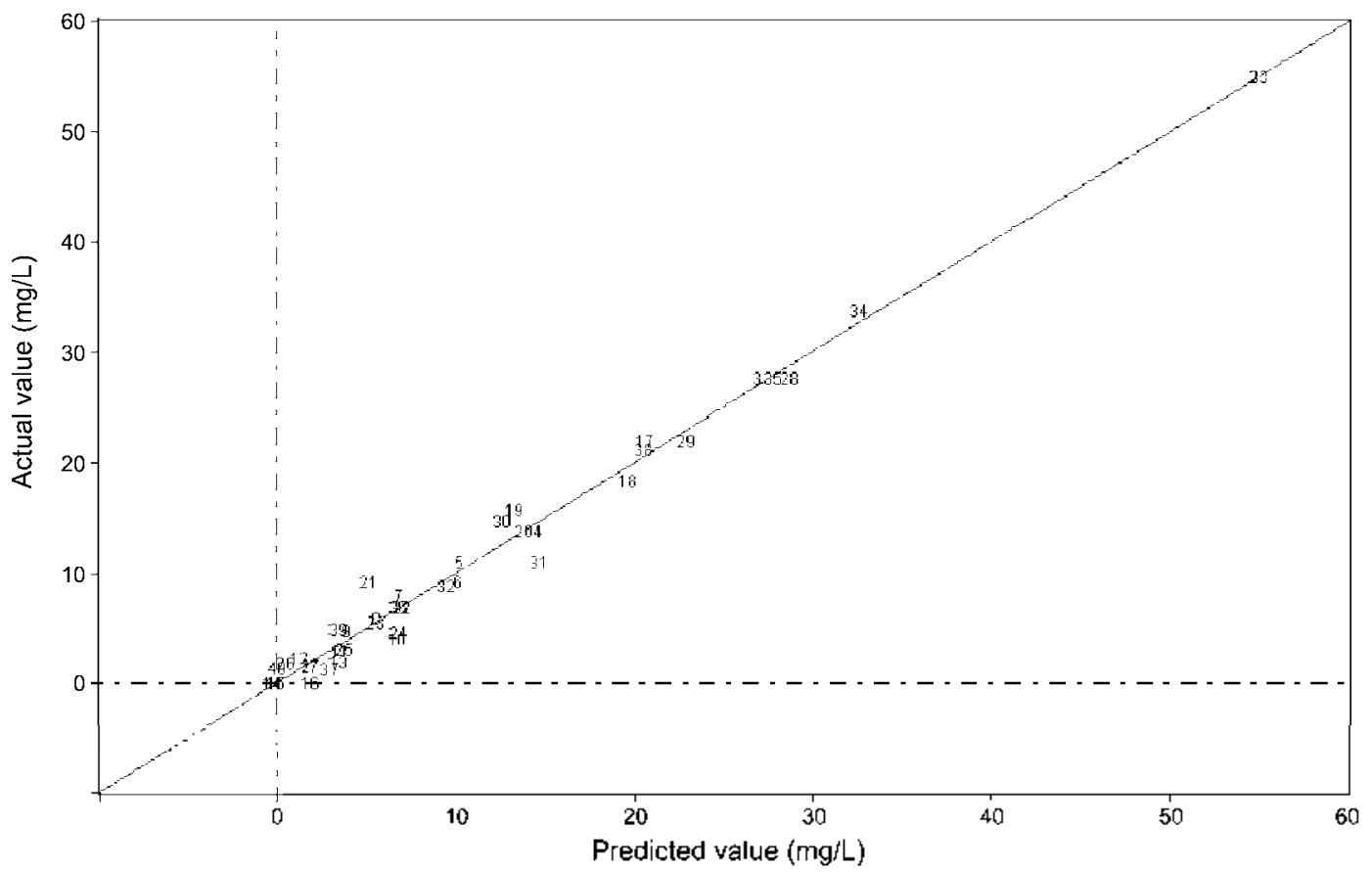

Figure 4. Relationship between the actual Benzo(ghi)perylene contents and the NIR predicted values by PLSR.

Table 1. Analytical results of PAHs detemined by FT-NIR using PLSR

\begin{tabular}{|c|c|c|c|c|c|}
\hline Compounds & $\mathrm{CVS}^{a}$ & $\begin{array}{l}\text { No. of } \\
\text { factor }\end{array}$ & Spectrum ${ }^{b}$ & $\mathrm{R}^{\mathrm{r}}$ & RMSEF $^{*}$ \\
\hline Total PAHs & 31 & 7 & 2nd derivate & 0.987 & 8.81 \\
\hline Benzo(a)pyrene & 46 & 9 & 2nd derivate & 0.957 & 6.35 \\
\hline Benzoig a anthracene & 34 & 1 & Absorbance & 0.888 & 10.60 \\
\hline Pyrene & 51 & 5 & Absorbance & 0.939 & 12.24 \\
\hline Benzo(ghi)perylene & 40 & 10 & Absorbance & 0.994 & 1.43 \\
\hline Anthracene & 42 & 10 & 2nd derivate & 0.985 & 7.85 \\
\hline Perylene & 29 & 3 & Absorbance & 0.953 & 5.80 \\
\hline Chrysene & 43 & 1 & Absorbance & 0.825 & 21.55 \\
\hline 1-Methylantluracene & 45 & 7 & 2nd derivate & 0.942 & 5.85 \\
\hline
\end{tabular}

"CVS (cross-validation segments) is the number of spectra selected for the calibration set. ${ }^{b}$ The type of spectrum used for PLSR. 'Correlation coefticient. "The unit is $\mathrm{mg} \mathrm{L}^{-1}$

observed for estimating the concentration of BaP.

Figure 3 shows the relationship between the actual total PAH contents ( $\mathrm{x}$ axis) and the NIR predicted values ( $y$ axis). Figure 4 shows the relationship between the actual contents of benzo(ghi)perylene and the NIR prediction values. A good correlation between the known concentrations and the NIR prediction values was obtained. The resulting value of correlation coefficient was 0.987 for the total PAHs. and 0.957 for the $\mathrm{BaP}$ (Refer to Table 1 ).

We also tried to estimate the concentration of each PAH. As shown in Table 1 the correlation coefficients were 0.888 . 0.939 .0 .994 .0 .985 .0 .953 .0 .825 and 0.942 for Benzo(a)anthracene py rene benzo(ghi)pery lene, anthracene perylene. clurysene. and 1-methylanthracene respectively: The PAHs with less than 4 benzene rings such as chrysene. anthracene and benzo(a)anthacene show slightly lower correlation coefficient and higher RMSEP. For the PAHs with more than 5 benzene rings (perylene and benzo(ghi)perylene) or with methyl functional group (l-methylantluracene) have higher correlation coefficient and lower RMSEP.

\section{Conclusion}

It was possible to determine each PAH using NIR spectroscopy using PLSR at the environmental level $\left(\mathrm{mg} \mathrm{L}^{-1}\right)$ using laboratory-generated samples. Further development will lead to evaluate the same NIR spectra for the more PAHs in typical environmental samples with complex matrix.

Acknowledgment. This work was supported by Korea Research Foundation Grant (KRF-2002-C00012).

\section{References}

1. Marriott, P. J.: Carpenter, P. D.; Brady, P. H.: McCormick, M. J.: Griftiths. A. T.: Hatvani. S. G.: Rasdell. S. G. J. Liq. Clmomatog: 1993. 16.3229.

2. Nam. J. T.: Lee. S. H. Bull. Konean Chem. Soc. 2002. 23.1097.

3. Noergaard, L. Talamta 1995. $12,1305$.

4. Hernändez. O.: Martin, E.: Jiménez. F.: Jiménez. A. I.: Arias. J. J. Andlyst 2000. 125, 1159 .

5. Hernández-Arteseros. J. A.: Compañó. R.: Ferrer. R.: Prat. M. D. Anohst 2000. 125. 1155.

6. Zwanziger. H. W. Sârbu. C. Anal Chent 1998. 70. 1277.

7. Defernez, M.: Wilson, R. H. Anal. Chem. 1997. 69, 1288.

8. Beebe. K. R.: Kowalski, B. R. Anal Chem 1987,59. 1007A.

9. Geladi. P. Kowalski, B. R. Anal. Chim. Acta 1986. 185. 1.

10. Despagne. F.: Massart. D. Anal. Chem 1997.69. 3391.

11. Ferre. T.: Rius. X Anal. Chem. 1996. 68. 1565.

12. Guiteras. J: Beltrát1. J. L:: Ferrer. R Anal. Chim . Acta 1998. 361. 233.

13. Beltran. J. L.: Guiteras. J.: Ferrer. R .Anal. Chem. 1998, 70, 1949. 